\title{
Is homeopathy a clinically valuable approach?
}

\section{Edzard Ernst}

Complementary Medicine, Peninsula Medical School, Universities of Exeter \& Plymouth, 25 Victoria Park Road, Exeter EX2 4NT, UK

\begin{abstract}
Homeopathy is a popular but implausible form of medicine. Contrary to many claims by homeopaths, there is no conclusive evidence that highly dilute homeopathic remedies are different from placebos. The benefits that many patients experience after homeopathic treatment are therefore most probably due to nonspecific treatment effects. Contrary to widespread belief, homeopathy is not entirely devoid of risk. Thus, the proven benefits of highly dilute homeopathic remedies, beyond the beneficial effects of placebos, do not outweigh the potential for harm that this approach can cause.
\end{abstract}

\section{The origins of homeopathy}

Christian Friedrich Samuel Hahnemann, the 'father' of homeopathy, was born in 1755, and 2005, 250 years following his birth, is a welcome occasion to enquire about the evidence base of homeopathy. Homeopathy is defined as 'a therapeutic method using preparations of substances whose effects when administered to healthy subjects correspond to the manipulation of the disorder (symptoms, clinical signs, pathological states) in the individual patient' [1]. It is based on two axioms: the 'like cures like principle' (as in the definition above) and the notion that 'potentiation' (serial dilution with vigorous shaking) renders a medicine not less and less but more and more powerful. Thus, many homeopathic remedies are diluted beyond Avogadro's number $\left(6.0225 \times 10^{23}\right)$ where the likelihood approaches zero that a single molecule of the original substance is contained in the remedy. Both axioms are scientifically implausible. The results of basic research occasionally seem to support some concepts of homeopathy [2] only to be refuted later. Indeed, a systematic review of preclinical studies concluded that 'in the few instances where a research team has set out to replicate the work of another, either the results were negative or the methodology was questionable' [3]. Many clinicians regard homeopathy as a 'benign deception' [4] but others argue that the homeopathic consultation could be of clinical value [5].

\section{The appeal of homeopathy}

Despite its implausibility, homeopathy became popular 200 years ago in Germany and France and later in several other countries, including the USA [6]. Considering that, at the time, many conventional treatments were worse

Corresponding author: Ernst, E. (Edzard.Ernst@pms.ac.uk).

Available online 13 September 2005 than the disease, the initial success of homeopathy is understandable; being highly dilute, most homeopathic remedies are largely free of adverse effects. The recent renaissance of homeopathy is perhaps more puzzling; it can be seen in the context of the global boom in all types of alternative medicine [7].

Today, $\sim 20 \%$ of all GPs and $90 \%$ of all veterinarians in Germany practise homeopathy. In the UK $42 \%$ of GPs refer patients to homeopaths and $86 \%$ of Scottish GPs are said to be in favor of homeopathy. In Holland, $45 \%$ of GPs use homeopathy and, in Belgium, this figure is reported to be $85 \%$. Across Europe approximately a quarter of the population uses homeopathy [8]. A Norwegian observational study suggested recently that 7 out of 10 patients who visited a homoeopath felt improvement in their main complaint 6 months after the initial consultation [9]. According to French survey data, homeopathy is used mainly in mental disorders, infections and rheumatological disorders [10].

\section{Is homeopathy more than a placebo?}

Popularity does not, of course, prove efficacy. A current draft World Health Organization (WHO) report on homeopathy concludes that 'a growing scientific evidence profile...suggests the effectiveness of homeopathy'. In light of the existing clinical evidence, this is a perplexing statement that urgently requires correction. Approximately 150 randomized clinical trials of homeopathy have been published to date, and their results are far from uniform. A 1997 meta-analysis of 89 studies found that overall 'clinical effects of homeopathy are not completely due to placebo' [11]. This article is still celebrated by homeopaths as the ultimate proof of efficacy. Yet, this view ignores the fact that six re-analyses of these data, including two by the original first author, found that these clinical trials by no means constitute proof of efficacy [12]. As new studies emerged, so did further $(n=11)$ systematic reviews; collectively, their results fail to show that homeopathic remedies are more than placebos [12]. The most recent systematic review in this area focuses on homeopathy for depression and concludes that the evidence is limited 'due to lack of clinical trials of high quality' [13].

Systematic reviews are prone to publication bias and poor methodological quality of the primary data. It is conceivable that the homeopathic community does not publish all studies that generated negative findings. One early and spectacular (but little-known) example of this 
phenomenon is Nazi Germany's attempt to evaluate homeopathy on a grand scale. Leading German scientists of the time were charged with testing homeopathy at a basic science level in addition to through clinical research. The results, which survived the war but later seem to have disappeared in the hands of homeopaths, were apparently wholly negative [14]. The frequently poor quality of clinical trials constitutes a further problem. Re-analyzing their own data, Linde et al. concluded that 'there was clear evidence that studies with better methodological quality tended to yield less positive results' [15].

\section{Perceived benefit versus efficacy}

Proponents and opponents of homeopathy alike are sometimes puzzled by this overt contradiction: on the one hand, patients feel improvement after homeopathic treatment; on the other hand, the best available clinical evidence fails to show that homeopathic remedies are superior to placebos. The most plausible explanation is that the therapeutic encounter with a homoeopath, often lasting one hour or longer, is highly inductive of nonspecific therapeutic effects, whereas highly diluted homeopathic remedies are devoid of specific therapeutic effects.

Some might argue that, if this is true, homeopathy might still be a clinically valuable approach. I counter that one does not need a placebo to generate a placebo response: treatments with specific therapeutic actions will also produce clinically meaningful placebo effects [16]. Is it then not better to profit from both specific and nonspecific therapeutic effects by prescribing treatments that have been shown to be superior to placebo?

\section{Is homeopathy totally devoid of risks?}

Even though homeopathic remedies are, as stated above, largely risk-free, the homeopathic approach is clearly capable of causing harm. If, for example, homeopaths prevent effective interventions, harm is likely to occur. A relatively well-researched example is the tendency of some homeopaths to advise mothers against the immunization of their children [17]. Another example of potential harm is the phenomenon of 'homeopathic aggravations'. If, following the 'like cures like' principle, a homoeopath administers the optimal remedy, about a quarter of patients are, according to homeopathic thinking, expected to experience 'homeopathic aggravations': that is, a 'healing crisis' where symptoms get worse before they get better [18]. From the patient's perspective and from a public health perspective, these aggravations must be regarded as adverse effects. The notion that homeopathy is entirely benign therefore seems to be misguided.

\section{Concluding remarks}

Therapeutic decisions should be based foremost on an assessment of the potential risk versus proven benefit. For homeopathy, the benefit side of this equation is currently not clearly defined: the best available evidence does not convincingly show benefits over and above those of placebo. The risks of homeopathy are probably relatively small. But even small risks can weigh heavy if the benefit is uncertain, small or totally absent. If one adds to all this, the scientific implausibility of the basic concepts that underlie homeopathic thinking, the inescapable conclusion is not positive: 250 years after the birth of its 'inventor', homeopathy is not associated with a riskbenefit profile that is demonstrably positive.

\section{References}

1 Swayne, J. (2002) International Dictionary of Homeopathy, Churchill Livingstone

2 Rey, L. (2003) Thermoluminescence of ultra-high dilutions of lithium chloride and sodium chloride. Physica Acta (Amsterdam) 323, 67-74

3 Vickers, A.J. (1999) Independent replication of pre-clinical research in homoeopathy: a systematic review. Forsch. Komplementarmed. 6, 311-320

4 Jeffries, D. (2005) Homeopathy - a benign deception? Br. J. Gen. Pract. 55,490

5 Williams, N. (2005) Homeopathy is where the heart is. Br. J. Gen. Pract. 55, 556

6 Ernst, E. and Kaptchuk, T.J. (1996) Homeopathy revisited. Arch. Intern. Med. 156, 2162-2164

7 Ernst, E. (2000) Prevalence of use of complementary/alternative medicine: a systematic review. Bull. World Health Organ. 78, 252-257

8 Medhurst, R. (2004) The use of homoeopathy around the world. J. Australian Traditional-Medicine Society 10, 153

9 Steinsbekk, A. and Lüdtke, R. (2005) Patients' assessments of the effectiveness of homeopathic care in Norway: a prospective observational multicentre outcome study. Homeopathy 94, 10-16

10 Colin, P. (2000) An epidemiological study of a homeopathic practice. Br. Homeopath. J. 89, 116-121

11 Linde, K. et al. (1997) Are the clinical effects of homoeopathy placebo effects? A meta-analysis of placebo-controlled trials. Lancet 350, 834-843

12 Ernst, E. (2002) A systematic review of systematic reviews of homeopathy. Br. J. Clin. Pharmacol. 54, 577-582

13 Pilkington, K. et al. (2005) Homeopathy for depression: a systematic review of the research evidence. Homeopathy 94, 153-163

14 Donner, F. (1995) Bemerkungen zu der Überprüfung der Homöopathie durch das Reichsgesundheitsamt 1936-1939. Perfusion 8, 3-7(Part 1), 35-40 (Part 2), 84-88 (Part 3), 124-129 (Part 4), 164-166 (Part 5)

15 Linde, K. et al. (1999) Impact of study quality on outcome in placebo controlled trials of homoeopathy. J. Clin. Epidemiol. 52, 631-636

16 Harkness, E.F. and Ernst, E. (2000) The enigmatic placebo effect - a systematic review to define its determinants. Perfusion 13, 164-170

17 Schmidt, K. and Ernst, E. (2003) MMR vaccination advice over the Internet. Vaccine 21, 1044-1047

18 Thompson, E. et al. (2004) A preliminary audit investigating remedy reactions including adverse events in routine homeopathic practice. Homeopathy 93, 203-209 